\title{
Treatment Challenges in Venous Thromboembolism: An Appraisal of Rivaroxaban Studies
}

\author{
Alok A. Khorana ${ }^{1}$ Jeffrey I. Weitz ${ }^{2}$ \\ ${ }^{1}$ Taussig Cancer Institute, Cleveland Clinic, 10201 Carnegie Avenue, \\ CA60, Cleveland, Ohio, United States \\ ${ }^{2}$ Thrombosis and Atherosclerosis Research Institute and McMaster \\ University, Hamilton, Ontario, Canada
}

Address for correspondence Alok A. Khorana, MD, Taussig Cancer Institute, Cleveland Clinic Foundation, 9500 Euclid Avenue, Cleveland, OH 44195, United States (e-mail: Khorana@ccf.org).

Thromb Haemost 2018;118 (Suppl 1):S23-S33.

\begin{abstract}
Venous thromboembolism (VTE) presents a continuing clinical burden to healthcare systems and there are patient groups for whom VTE management is challenging. Depending on the patient profile, the optimal duration of anticoagulation for VTE treatment can be unclear. EINSTEIN CHOICE was a Phase III, randomized, double-blind trial that compared the safety and efficacy of two once-daily (od) doses of the direct, oral factor Xa inhibitor rivaroxaban (20 and $10 \mathrm{mg}$ ) with acetylsalicylic acid (ASA; $100 \mathrm{mg}$ daily) for prevention of recurrent VTE. Extended therapy with rivaroxaban at either dose was more effective than ASA at preventing recurrent VTE without increasing bleeding risk. Another group that is challenging to treat in the context of VTE is patients with cancer-associated thrombosis. Cancer is associated with a hypercoagulable state, while cancer treatment itself may increase VTE risk. Evidence

Keywords

- anticoagulation

- extended treatment

- cancer-associated thrombosis

- venous thromboembolism

- rivaroxaban supporting the use of non-vitamin $\mathrm{K}$ antagonist oral anticoagulants in patients with cancer is growing through specifically designed studies. Cancer Associated thrombosis -expLoring soLutions for patlentS through Treatment and prevention with rivarOxaban (CALLISTO) is an international research program exploring the role of rivaroxaban for the prevention and treatment of cancer-associated thrombosis. Here, we present overviews of three CALLISTO studies: PRO-LAPS II, CASTA-DIVA and COSIMO. Currently available and anticipated results from studies in a variety of patients at risk of or with VTE will provide valuable insights and seek to optimize future VTE management.
\end{abstract}

\section{Introduction}

Venous thromboembolism (VTE) is a major cause of morbidity and mortality worldwide. In Europe, it is estimated that VTE is responsible for 544,000 deaths each year. ${ }^{1}$ Estimates from the United States suggest that 350,000 to 600,000 patients suffer from VTE each year and up to 100,000 die from their disease. ${ }^{2}$ For hospitalized patients, VTE is the second most common medical complication, the second most common cause of prolonged hospital stay and the third most common cause of in-hospital death. ${ }^{3}$ VTE predominantly affects older patients; therefore, the global burden of VTE is expected to increase due to an aging population. ${ }^{4,5}$

Anticoagulants are the cornerstone of VTE treatment and the American College of Chest Physicians (ACCP) gives preference to the non-vitamin $\mathrm{K}$ antagonist oral anticoagulants (NOACs) over vitamin Kantagonists (VKAs) such as warfarin for such therapy. ${ }^{6}$ Treatment is given for at least 3 months at which point the decision to extend therapy is made based on the balance between the risk of recurrent VTE if anticoagulation is received

September 29, 2017

accepted after revision

November 6, 2017
Copyright @ 2018 Schattauer

DOI https://doi.org/ 10.1160/TH17-09-0681. ISSN $0340-6245$. 
stopped and the risk of bleeding if anticoagulation is continued. Patient preference also factors into the decision. Fear of bleeding often leads to reluctance to extend anticoagulant therapy beyond 3 to 6 months, and a major challenge is identifying patients who would benefit most from extended treatment. ${ }^{6}$

A second knowledge gap is how to best manage VTE in patients with cancer. Up to $20 \%$ of patients with VTE have underlying cancer, ${ }^{7,8}$ and cancer-associated thrombosis (CAT) is the second leading cause of death in such patients. In addition, the diagnosis of VTE in cancer patients may delay cancer treatments, prolong hospital stay and increase healthcare costs. ${ }^{9-11}$ Current guidelines give preference to low-molecular-weight heparin (LMWH) over VKAs or NOACs for the treatment of CAT based on limited data from randomized trials comparing NOACs with VKAs in such patients and the absence of trials comparing NOACs with LMWH for CAT treatment. ${ }^{6}$

In this review, we identify the areas of unmet clinical needs in these areas and highlight the various trials and initiatives that have investigated, or are currently investigating, rivaroxaban for the extended treatment of VTE (EINSTEIN CHOICE) and the management of CAT (Cancer Associated thrombosisexpLoring soLutions for patlentS through Treatment and prevention with rivarOxaban [CALLISTO]).

\section{Prevention of Recurrent VTE: An Unmet Need}

VTE includes deep-vein thrombosis (DVT) and pulmonary embolism (PE). The risk of recurrent VTE can increase over time if anticoagulation therapy is stopped. Indeed, rates of recurrence at 1,5 and 10 years after stopping anticoagulation following a first episode of clinically symptomatic proximal DVT and/or PE are in the order of 10,30 and $40 \%$, respectively. ${ }^{12}$ In particular, the risk of recurrent VTE reaches more than twofold in patients with unprovoked VTE. ${ }^{12}$ Furthermore, the mortality rate in those who experience recurrent VTE events is more than $10 \% .{ }^{12}$ Although extended anticoagulation therapy reduces the risk of recurrence by at least $80 \%$, there is still controversy regarding which patients should receive such treatment. ${ }^{6,13}$

Rivaroxaban, which inhibits factor Xa, is licensed for the initial, long-term and extended treatment of VTE, based on the results of the Phase III EINSTEIN clinical trial program. ${ }^{14,15}$ Compared with conventional treatment consisting of enoxaparin overlapped with a VKA, the EINSTEIN DVT and PE trials showed that rivaroxaban (starting at a dose of $15 \mathrm{mg}$ twice daily [bid] for 21 days followed by $20 \mathrm{mg}$ once daily [od] thereafter) was as effective for prevention of recurrent VTE and was associated with a $50 \%$ decrease in major bleeding. ${ }^{14,15}$ Furthermore, rivaroxaban is easier to administer than enoxaparin followed by a VKA because it can be given orally in fixed doses without routine coagulation monitoring. ${ }^{16}$

EINSTEIN EXT compared the efficacy and safety of rivaroxaban (20 mg od) and placebo for the prevention of recurrent VTE in patients who had already completed 6 to 12 months of anticoagulant therapy for their index event and for whom there was equipoise about the need for continued treatment. Extended treatment with rivaroxaban or placebo was given for
6 or 12 months. ${ }^{14}$ Compared with placebo, rivaroxaban was superior and produced an $82 \%$ reduction in the rate of recurrent symptomatic VTE (hazard ratio [HR]: 0.18; $95 \%$ confidence interval [CI]: 0.09-0.39; $p<0.001$ ) and was associated with a low rate of major bleeding that was not significantly higher than that observed with placebo $(0.7$ and $0 \%$, respectively; $p=0.11) .{ }^{14}$

Clinical guidelines from the ACCP endorse treatment with NOACs (including rivaroxaban, apixaban, edoxaban and dabigatran) in preference to VKAs for the initial and long-term (first 3 months) treatment of VTE in patients without cancer. ${ }^{6}$ However, these guidelines only suggest (rather than recommend) extending therapy beyond 3 months in patients with a first unprovoked VTE and low to moderate bleeding risk. $^{6}$ Three months is recommended as the duration of anticoagulation for all other VTE patients without cancer. ${ }^{6}$

Acetylsalicylic acid (ASA) was compared with placebo for secondary prevention of unprovoked VTE in the Warfarin and Aspirin (WARFASA) and Aspirin to Prevent Recurrent Venous Thromboembolism (ASPIRE) trials. Patients enrolled in these trials had completed 6 weeks to 24 months (ASPIRE) or 6 to 18 months (WARFASA) of anticoagulation therapy for their index VTE event. ${ }^{17}$ A combined analysis of the results of these two trials showed that ASA significantly reduced the incidence of recurrent VTE compared with placebo by $32 \%$ (HR: 0.68 ; 95\% CI: $0.51-0.90 ; p=0.007$ ), without significantly increasing the rate of major bleeding. ${ }^{17}$ The current ACCP guidelines suggest the use of ASA in patients with unprovoked proximal DVT or PE who elect to stop anticoagulant therapy, and do not have a contraindication to ASA. ${ }^{6}$

EINSTEIN CHOICE was designed to determine whether an alternative lower rivaroxaban dose $(10 \mathrm{mg}$ od) would provide a similar balance of efficacy and safety as rivaroxaban $20 \mathrm{mg}$ od in offering extended protection from recurrent VTE compared with ASA. ${ }^{18,19}$

\section{EINSTEIN CHOICE: Rivaroxaban for the Extended Treatment of VTE}

EINSTEIN CHOICE was a Phase III, randomized, double-blind trial that compared the safety and efficacy of two different doses of once-daily rivaroxaban (20 and $10 \mathrm{mg}$ ) with ASA (100 mg daily) for the prevention of recurrent VTE. ${ }^{18,19}$ The 20 -mg od dose of rivaroxaban was chosen because it was shown to be superior to placebo for the prevention of recurrent VTE in the EINSTEIN EXT trial, and the 10-mg od dose of rivaroxaban was chosen because at that dose rivaroxaban was studied as thromboprophylaxis after hip or knee replacement surgery and in medically ill patients. ${ }^{14,16,18,19}$ ASA was used as a comparator because compared with placebo, it reduced the risk of recurrent VTE by $32 \%$ in previous trials. ${ }^{17}$ Patients included in EINSTEIN CHOICE had completed 6 to 12 months of anticoagulation therapy for their index VTE event and had equipoise regarding the need for continued anticoagulation. Study drugs were administered for up to 12 months, with a 1 -month follow-up. The primary efficacy outcome was symptomatic recurrent fatal or nonfatal VTE; the principal safety outcome was major bleeding. ${ }^{18,19}$ 


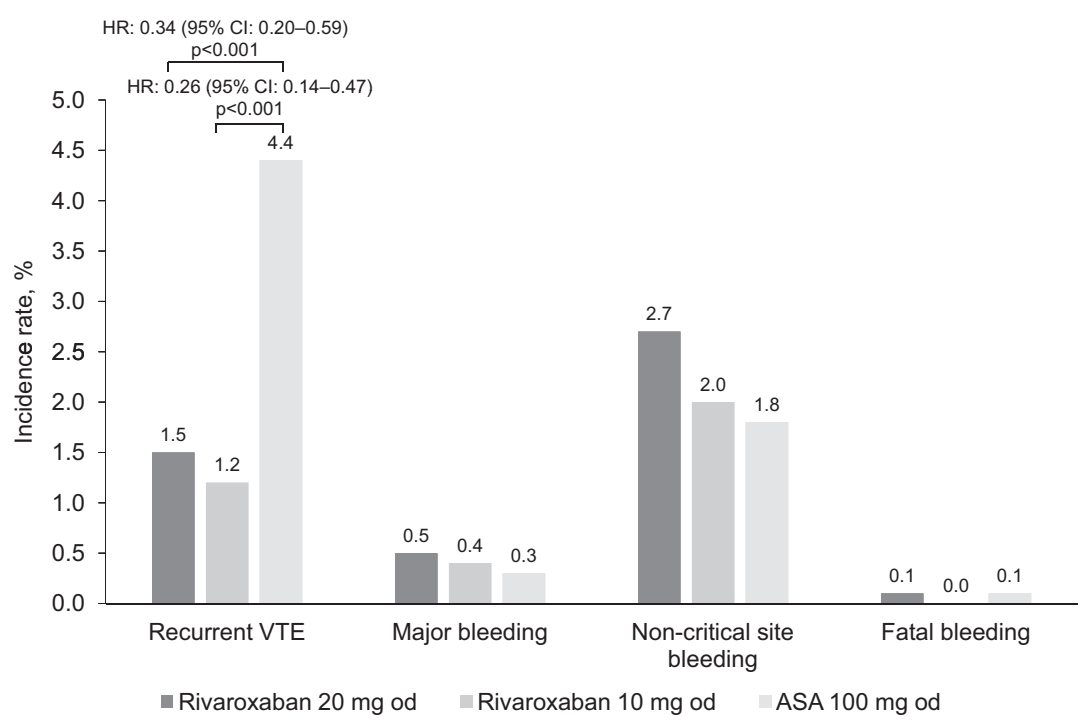

Fig. 1 Key primary outcomes in EINSTEIN CHOICE. ${ }^{19}$ Abbreviations: ASA, acetylsalicylic acid; Cl, confidence interval; HR, hazard ratio; od, once daily; VTE, venous thromboembolism.

A total of 3,365 patients with a median treatment duration of 351 days were included in the intention-to-treat analysis. ${ }^{19}$ The primary efficacy outcome occurred in 17 of 1,107 patients (1.5\%) receiving rivaroxaban $20 \mathrm{mg}$ od and in 13 of 1,127 patients (1.2\%) receiving rivaroxaban $10 \mathrm{mg}$ od, compared with 50 of 1,131 patients (4.4\%) receiving ASA (HR for rivaroxaban $20 \mathrm{mg}$ od vs. ASA: 0.34; 95\% CI: 0.20-0.59; HR for rivaroxaban $10 \mathrm{mg}$ od vs. ASA: 0.26 ; $95 \% \mathrm{CI}: 0.14-0.47$; $p<0.001$ for both comparisons; - Fig. 1). The rates of major and clinically relevant non-major (CRNM) bleeding were not significantly different among the three groups (major bleeding HR for rivaroxaban $20 \mathrm{mg}$ od vs. ASA: $2.01 ; 95 \% \mathrm{CI}$ : 0.50-8.04, $p=0.32$; major bleeding HR for rivaroxaban $10 \mathrm{mg}$ od vs. ASA: 1.64; 95\% CI: 0.39-6.84, $p=0.50$; CRNM bleeding HR for rivaroxaban $20 \mathrm{mg}$ od vs. ASA: 1.53 ; $95 \% \mathrm{CI}: 0.87-2.69$, $p=0.14$; CRNM bleeding HR for rivaroxaban $10 \mathrm{mg}$ od vs. ASA: 1.09 ; 95\% CI: $0.59-2.00, p=0.78$ ). The incidences of noncritical and fatal bleeding were similar between groups (-Fig. 1), as were the incidences of adverse events. Thus, compared with ASA, both doses of rivaroxaban significantly reduced the risk of recurrent VTE by approximately $70 \%$ without a significant increase in the rate of major bleeding. ${ }^{19}$

Although the differences in the rates of major plus CRNM bleeding with the 20-mg and 10-mg doses of rivaroxaban were not statistically significant $(p=0.21)$, there were fewer such bleeding events with the 10-mg dose than with the 20mg dose (27/1,127 [2.4\%] vs. 36/1,107 [3.3\%], respectively). ${ }^{19}$ In addition, in women who entered into the trial, the intensity and duration of menstrual bleeding events reported with the 10-mg dose were less than those with the 20-mg dose and were similar to the intensity and duration of menstrual bleeding reported with ASA. ${ }^{20}$ Therefore, rivaroxaban $10 \mathrm{mg}$ od may have safety advantages over rivaroxaban $20 \mathrm{mg}$ od for extended VTE treatment in patients at risk of bleeding.
EINSTEIN CHOICE included patients with provoked and unprovoked VTE. The recurrence risk in unprovoked VTE is clearly high, while the risk of recurrence remains less clear in those whose VTE was provoked by minor transient or persistent risk factors. So while the results appeared favorable for both groups of patients, clinicians need further clarity on the situations in which extended VTE treatment should be given to those with provoked VTE. In addition, patients who required extended treatment with therapeutic doses of anticoagulant agents were excluded. Therefore, it remains unknown whether rivaroxaban $10 \mathrm{mg}$ od would be sufficient to prevent recurrence in such patients.

Findings from EINSTEIN CHOICE led to label updates by both the European Medicines Agency and the Food and Drug Administration to include extended prevention of recurrent VTE with rivaroxaban $10 \mathrm{mg}$ od following $\geq 6$ months of standard anticoagulation therapy. ${ }^{21,22}$ Rivaroxaban $20 \mathrm{mg}$ od could potentially be continued in patients at high risk for VTE recurrence, for example those whose index VTE event was life-threatening, those with a high risk of thrombophilia, or those who had a recurrence of VTE while receiving other anticoagulants or lower doses of the same anticoagulant. Therefore, with the availability of the two doses of rivaroxaban, the intensity of extended anticoagulation therapy can be individualized based on the relative risks of recurrent VTE and bleeding.

Similar data are available for apixaban. Thus, in the randomized, double-blind Apixaban after the Initial Management of Pulmonary Embolism and Deep Vein Thrombosis with FirstLine Therapy-Extended Treatment (AMPLIFY-EXT) trial, two doses of apixaban ( $2.5 \mathrm{mg}$ bid and $5 \mathrm{mg}$ bid) were compared with placebo for the prevention of recurrence in patients with VTE who had completed 6 to 12 months of anticoagulation therapy and for whom there was equipoise regarding the need for continued anticoagulation therapy. Study drugs were 
administered for 6 months. ${ }^{23}$ Compared with placebo, the prophylactic dose of apixaban ( $2.5 \mathrm{mg}$ bid) was as effective as the treatment dose ( $5 \mathrm{mg}$ bid) for prevention of recurrence, and both doses were associated with rates of major and CRNM bleeding similar to those with placebo. ${ }^{23}$ Therefore, in clinical practice, the intensity of VTE treatment with apixaban or rivaroxaban could be tailored in line with the risk of recurrence: a higher dose for initial therapy when the risk of recurrence is greatest (apixaban $10 \mathrm{mg}$ bid for 7 days or rivaroxaban $15 \mathrm{mg}$ bid for 21 days), followed by a treatment dose for 3 to 6 months (apixaban $5 \mathrm{mg}$ bid or rivaroxaban $20 \mathrm{mg}$ od), and then a lower dose for an extended duration to ensure long-term protection (apixaban $2.5 \mathrm{mg}$ bid or rivaroxaban $10 \mathrm{mg}$ od).

\section{Prevention and Treatment of CAT: An Unmet Need}

Cancer is associated with a hypercoagulable state resulting from multiple factors, both related to the cancer itself and anticancer therapies. ${ }^{24}$ CAT is a common cause of morbidity and mortality in patients with malignancy. $7,8,11,25$ When treated with conventional therapy consisting of heparin followed by a VKA, patients with CAT are at higher risk of both recurrent VTE and bleeding than VTE patients without cancer. ${ }^{26}$ The treatment of CAT with anticoagulants can be complicated by concurrent systemic therapy, and the need for treatment interruption for invasive diagnostic and other procedures. Individualized anticoagulant treatment duration is based on the clinical status and stage of cancer, the risk of recurrent VTE and bleeding, and patient preference. ${ }^{27,28}$

Risk factors for VTE in cancer patients include the type and stage of cancer, older age, poor performance status, prior history of VTE, presence of a central venous catheter or port, extent of surgery and type of cancer treatment. Hospitalized patients and those receiving chemotherapy are at highest risk of CAT. ${ }^{7,11,29,30}$

Various guidelines are available for the prevention and treatment of CAT and differ depending on the patient group (-Table 1). Guidelines from the ACCP for VTE prevention recommend 4 weeks of thromboprophylaxis with LMWH or fondaparinux after extensive abdominal or pelvic surgery for cancer. ${ }^{31}$ However, in practice, LMWH is usually stopped when patients are discharged. ${ }^{32}$ Routine thromboprophylaxis is not recommended for ambulatory cancer patients except in selected high-risk patients, such as those with multiple myeloma receiving anti-angiogenesis agents with chemotherapy and/or dexamethasone, where prophylaxis with LMWH or low-dose ASA is recommended. ${ }^{32-34}$ The Haemostasis and Thrombosis Task Force of the British Committee for Standards in Haematology (BCSH) and the European Society for Medical Oncology (ESMO) advise against routine anticoagulant thromboprophylaxis in patients receiving chemotherapy. ${ }^{33-35}$ While the role of primary prophylaxis in some cancer patients is uncertain (i.e. ambulatory patients or those receiving chemotherapy), the availability of scores to identify cancer patients at high risk of VTE (i.e. Khorana score), ${ }^{36}$ as well as the availability of
NOACs, renders ongoing trials of thromboprophylaxis feasible. The Khorana score is currently recommended for assessment of risk based on external validation in over 12,000 patients. ${ }^{37}$ Modifications of this score including PROTECHT and Vienna have been proposed but have not been validated. ${ }^{37}$ Ongoing studies of novel biomarker development may improve the performance of this score in risk stratification, but for now this remains the only validated score recommended by guidelines and is currently the basis of several ongoing randomized trials. ${ }^{37}$

For treatment of VTE in patients with active cancer, the American Society of Clinical Oncology (ASCO), BCSH and ESMO also give preference to LMWH over VKAs and recommend LMWH for at least 6 months. ${ }^{32-34}$ The ACCP guidelines recommend LMWH for initial treatment (the first 3 months), ${ }^{6}$ while recommending extended anticoagulation (no scheduled stop date) for patients without a high bleeding risk and suggesting extended anticoagulation for those with a high bleeding risk. ${ }^{6}$ The preference for LMWH is based on the results of several randomized controlled trials (RCTs) that demonstrated lower rates of recurrence with LMWH than with VKAs in patients with CAT, although the most contemporary of these studies did not meet its primary endpoint. ${ }^{38-40}$ While ASCO does not currently recommend NOACs for VTE treatment in patients with active cancer owing to insufficient evidence, the ACCP guidelines now include NOACs as part of the guidelines for anticoagulation in patients with VTE and cancer within the first 3 months after the VTE event, where LMWH is suggested over VKAs (Grade 2B) and dabigatran, rivaroxaban, apixaban or edoxaban (Grade 2C). ${ }^{6,32}$

While LMWH is the first choice for the treatment of CAT, the requirement for parenteral administration is a recognized limitation in addition to being resource intensive and inconvenient. ${ }^{41}$ Moreover, the risk of VTE recurrence associated with 6 months of LMWH in cancer patients has been estimated to be 7 to $8 \%$ in clinical trials. ${ }^{39,40}$ VKAs have shown lower efficacy than LMWH for the treatment of CAT and limitations include: a narrow therapeutic dosing window; the need for frequent monitoring and dose adjustments; interactions with food and drugs (including chemotherapy); and wide fluctuations in the international normalized ratio in those with hepatic metastases. ${ }^{34,35}$

The limitations of LMWH and VKAs may result in poor adherence to the anticoagulant therapies recommended in international clinical guidelines. A recent real-world study investigated how frequently the current guidelines are followed by assessing anticoagulation treatment patterns for VTE in newly diagnosed cancer patients in the United States. ${ }^{42}$ Findings showed that VTE occurred in $6.2 \%$ of this study population, with a median onset of 181 days after a cancer diagnosis. ${ }^{42}$ Outpatient prescription data showed that warfarin was the most commonly prescribed anticoagulant (50\%), followed by LMWH (40\%) and other anticoagulants (10\%). During a 6-month period, $13 \%$ of patients persisted on injectable anticoagulants compared with $30 \%$ who persisted on oral anticoagulants-this may be due to the burden of daily selfinjection and the high cost of LMWH in the United States. ${ }^{42}$ 
Table 1 Guidelines for prevention and treatment of CAT

\begin{tabular}{|c|c|c|c|c|c|}
\hline & $\mathrm{ACCP}^{6,31}$ & $\mathrm{ASCO}^{32}$ & $\mathrm{BCSH}^{33}$ & $\mathrm{ESC}^{60}$ & $\mathrm{ESMO}^{34}$ \\
\hline $\begin{array}{l}\text { VTE } \\
\text { prevention: } \\
\text { hospitalized } \\
\text { patients with } \\
\text { cancer }\end{array}$ & $\begin{array}{l}\text { Patients at high risk for } \\
\text { VTE undergoing } \\
\text { abdominal or pelvic } \\
\text { surgery for cancer: } \\
\text { recommend extended- } \\
\text { duration, postoperative, } \\
\text { pharmacologic } \\
\text { prophylaxis ( } 4 \text { wk) with } \\
\text { LMWH over limited- } \\
\text { duration prophylaxis } \\
\text { (Grade } 1 B \text { ) }\end{array}$ & $\begin{array}{l}\text { Hospitalized patients with } \\
\text { active malignancy with } \\
\text { acute medical illness or } \\
\text { reduced mobility: } \\
\text { thromboprophylaxis in } \\
\text { the absence of bleeding } \\
\text { or other contraindications } \\
\text { (strong evidence) } \\
\text { Thromboprophylaxis may } \\
\text { be considered in those } \\
\text { without additional risk } \\
\text { factors (moderate } \\
\text { evidence) } \\
\text { Patients undergoing } \\
\text { major cancer surgery: } \\
\text { prophylaxis with LMWH or } \\
\text { UFH starting before } \\
\text { surgery and continuing } \\
\text { for at least } 7-10 \mathrm{~d} \text { (strong } \\
\text { evidence) }\end{array}$ & $\begin{array}{l}\text { Thromboprophylaxis } \\
\text { for patients with active } \\
\text { or recent cancer } \\
\text { admitted to hospital } \\
\text { (2C) }\end{array}$ & $\mathrm{N} / \mathrm{A}$ & $\begin{array}{l}\text { Hospitalized cancer } \\
\text { patients confined to } \\
\text { bed with an acute } \\
\text { medical } \\
\text { complication: } \\
\text { thromboprophylaxis } \\
\text { with UFH, LMWH or } \\
\text { fondaparinux (IA) }\end{array}$ \\
\hline $\begin{array}{l}\text { VTE } \\
\text { prevention: } \\
\text { ambulatory } \\
\text { patients } \\
\text { with cancer }\end{array}$ & $\mathrm{N} / \mathrm{A}$ & $\begin{array}{l}\text { Thromboprophylaxis is } \\
\text { not routinely } \\
\text { recommended for } \\
\text { ambulatory patients with } \\
\text { cancer; it may be } \\
\text { considered for very select } \\
\text { high-risk patients } \\
\text { (moderate evidence) } \\
\text { Patients with multiple } \\
\text { myeloma receiving } \\
\text { antiangiogenesis agents } \\
\text { with chemotherapy and/ } \\
\text { or dexamethasone: } \\
\text { prophylaxis with either } \\
\text { LMWH or low-dose ASA } \\
\text { (moderate evidence) }\end{array}$ & $\begin{array}{l}\text { Recommend against } \\
\text { routine } \\
\text { thromboprophylaxis in } \\
\text { ambulatory cancer } \\
\text { patients, unless they } \\
\text { are high risk (2B) }\end{array}$ & $\mathrm{N} / \mathrm{A}$ & $\begin{array}{l}\text { Recommend against } \\
\text { routine } \\
\text { thromboprophylaxis } \\
\text { in ambulatory } \\
\text { patients receiving } \\
\text { chemotherapy; } \\
\text { suggest it may be } \\
\text { considered in high- } \\
\text { risk patients (IIC) } \\
\text { Myeloma patients } \\
\text { receiving } \\
\text { thalidomide plus } \\
\text { dexamethasone or } \\
\text { thalidomide plus } \\
\text { chemotherapy: } \\
\text { consider LMWH, ASA } \\
\text { or adjusted-dose } \\
\text { warfarin (INR } \sim 1.5 \text { ) } \\
\text { (IIB) }\end{array}$ \\
\hline $\begin{array}{l}\text { Treatment } \\
\text { andsecondary } \\
\text { prevention of } \\
\text { CAT }\end{array}$ & $\begin{array}{l}\text { Initial treatment (first } \\
3 \text { mo): suggest LMWH } \\
\text { over VKA (Grade 2B), } \\
\text { dabigatran (Grade 2C), } \\
\text { rivaroxaban (Grade 2C), } \\
\text { apixaban (Grade 2C) or } \\
\text { edoxaban (Grade 2C) } \\
\text { Extended (no scheduled } \\
\text { stop date) } \\
\text { anticoagulation: } \\
\text { recommended in patients } \\
\text { who do not have a high } \\
\text { bleeding risk (Grade IB), } \\
\text { and suggested for those } \\
\text { with a high bleeding risk } \\
\text { (Grade 2B) }\end{array}$ & $\begin{array}{l}\text { Initial treatment: LMWH } \\
\text { preferred over UFH for the } \\
\text { initial } 5-10 \mathrm{~d}^{\mathrm{b}} \text { (strong } \\
\text { evidence) } \\
\text { Long-term: LMWH for } \\
\geq 6 \text { mo is preferred over } \\
\text { VKAs }{ }^{\mathrm{c}, \mathrm{d}} \text { (strong evidence) } \\
\text { Use of NOACs is not } \\
\text { currently recommended } \\
\text { for patients with } \\
\text { malignancy and VTE } \\
\text { (insufficient evidence) }\end{array}$ & $\begin{array}{l}\text { Initial treatment } \\
\text { should be with LMWH } \\
\text { for six mo, if tolerated } \\
(1 \mathrm{~A}) \\
\text { active malignancy: } \\
\text { anticoagulation should } \\
\text { be continued, taking } \\
\text { patient status and } \\
\text { wishes and bleeding } \\
\text { risk into consideration }\end{array}$ & $\begin{array}{l}\text { Patients with PE } \\
\text { and cancer: } \\
\text { weight-adjusted } \\
\text { LMWH should be } \\
\text { considered for the } \\
\text { first 3-6 mo } \\
\text { (Ila, B) } \\
\text { Extended } \\
\text { anticoagulation } \\
\text { should be } \\
\text { considered for an } \\
\text { indefinite period } \\
\text { or until the cancer } \\
\text { is cured (Ila, C) }\end{array}$ & $\begin{array}{l}\text { Long-term } \\
\text { anticoagulation with } \\
\text { LMWH for six mo } \\
\text { (IIA) }\end{array}$ \\
\hline
\end{tabular}

${ }^{a}$ Extending postoperative prophylaxis up to 4 weeks should be considered in those with high-risk features;

${ }^{\mathrm{b}}$ Patients with cancer and newly diagnosed VTE who have $\mathrm{CrCl}>30 \mathrm{ml} / \mathrm{min}$;

'VKAs are an acceptable alternative for long-term therapy if LMWH is not available;

${ }^{\mathrm{d}}$ Anticoagulation with LMWH or VKA beyond 6 months may be considered for select patients with active cancer, e.g. those with metastatic disease or those receiving chemotherapy (insufficient evidence);

eWarfarin and other oral anticoagulants are acceptable alternatives if LMWH is impractical and anticoagulation is indicated $(1 \mathrm{~A})$.

Abbreviations: ACCP, American College of Chest Physicians; ASA, acetylsalicylic acid; ASCO, American Society for Clinical Oncology; BCSH, British Committee for Standards in Haematology; $\mathrm{CrCl}$, creatinine clearance; CAT, cancer-associated thrombosis; d, days; ESC, European Society of Cardiology; ESMO, European Society for Medical Oncology; INR, international normalized ratio; LMWH, low-molecular-weight heparin; mo, months; N/A, not applicable; NOAC, non-vitamin K antagonist oral anticoagulant; PE, pulmonary embolism; UFH, unfractionated heparin; VKA, vitamin K antagonist; VTE, venous thromboembolism; wk, weeks. 
Another recent real-world analysis showed that, despite guideline recommendations, warfarin and rivaroxaban were at least as equally utilized as LMWH for the treatment of CAT; LMWH was associated with significantly lower persistence, shorter duration of treatment and more requirements for switching compared with warfarin or rivaroxaban. ${ }^{43}$

It is likely that NOACs will present a simple and less costly option than LMWH for the treatment of CAT. Patients with cancer were included in Phase III trials which compared NOACs with VKAs for the treatment of VTE, suggesting that NOACs present a viable alternative to VKAs in this setting. ${ }^{44-48}$ Despite the fact that these trials were not designed to study patients with cancer specifically, or to compare NOACs with LMWH, the data available so far appear favorable, ${ }^{45,49}$ and further evidence to support NOAC use in CAT is growing. Studies underway include HOKUSAI-VTE Cancer (edoxaban vs. dalteparin), ADAM-VTE (apixaban vs. dalteparin), CARAVAGGIO (apixaban vs. dalteparin) and CANVAS (rivaroxaban, apixaban, edoxaban or dabigatran vs. LMWH or warfarin). ${ }^{50-53}$ Investigations into the efficacy and safety of rivaroxaban in CAT are the subject of the ongoing CALLISTO clinical research program. ${ }^{54}$

\section{The CALLISTO Program: Rivaroxaban for the Prevention and Treatment of VTE in Active Cancer}

CALLISTO is an international clinical research program addressing clinical questions in CAT via multiple studies, expert recommendations and clinical registries. ${ }^{54}$ The overall aim is to explore the potential of rivaroxaban in the prevention and treatment of CAT with a view to improving the quality of care for these patients. ${ }^{54}$

Studies in the CALLISTO program are summarized in - Table 2. They aim to address the following knowledge gaps for rivaroxaban: effectiveness and safety for the prevention and treatment of CAT; patient treatment satisfaction, treatment persistence and quality of life in cancer patients; effectiveness and safety for extended treatment ( $>6$ months) of CAT; treatment dosing in patients with chemotherapy-induced side effects; current strategies for thromboprophylaxis; management of temporary interruptions of rivaroxaban for invasive procedures and provision of continuous anticoagulation for patients with chemotherapy-induced side effects.

Three CALLISTO studies are described in more detail below: PRO-LAPSII, an RCT with rivaroxaban for the prevention of CAT; CASTA-DIVA, an RCT with rivaroxaban for treatment of CAT; and COSIMO, a noninterventional study (NIS) to assess patient-reported treatment satisfaction with rivaroxaban for patients with VTE and active cancer who transition to rivaroxaban therapy. ${ }^{55-57}$

\section{PRO-LAPS II: Rivaroxaban or Placebo for Extended Antithrombotic Prophylaxis after Laparoscopic Surgery for Colorectal Cancer}

The primary aim of PRO-LAPS II-a Phase III, investigatorinitiated, multicentre, randomized, double-blind, placebo- controlled trial-is to assess the efficacy and safety of postdischarge extended (3 weeks) antithrombotic prophylaxis with rivaroxaban $10 \mathrm{mg}$ od vs. placebo after planned laparoscopic surgery for colorectal cancer in patients who had received antithrombotic prophylaxis with LMWH administered for $7 \pm 2$ days following surgery. ${ }^{55}$ The primary outcome is a composite of symptomatic objectively confirmed VTE, asymptomatic ultrasonography-confirmed DVT and VTE-related death at $28 \pm 2$ days after planned laparoscopic surgery. ${ }^{55}$ Approximately 650 patients are anticipated to be enrolled in PRO-LAPS II. ${ }^{55}$ - Fig. 2 shows the study design for PRO-LAPS II.

\section{CASTA-DIVA: Efficacy and Safety of Oral Rivaroxaban for the Treatment of VTE in Patients with Active Cancer. A Pilot Study}

CASTA-DIVA is a prospective, multicentre, randomized, openlabel, noninferiority pilot trial with blinded adjudication of endpoints. ${ }^{56}$ The aim of the study is to compare the efficacy and safety of rivaroxaban ( $15 \mathrm{mg}$ bid for 21 days, then $20 \mathrm{mg}$ od) and dalteparin (200 IU/kg for 4 weeks, then $150 \mathrm{IU} / \mathrm{kg}$ ) for the treatment of VTE in patients with active cancer at high risk of VTE recurrence, defined by a modified Ottawa score. The primary outcome is recurrent VTE, including all symptomatic or incidental DVT/PE and worsening of pulmonary vascular obstruction or venous obstruction. The secondary outcomes include major bleeding, as defined using the International Society on Thrombosis and Haemostasis (ISTH) criteria, CRNM bleeding, symptomatic recurrent PE or DVT, and pharmacokinetic parameters. Approximately 200 patients with active cancer are anticipated for enrolment in CASTA-DIVA. ${ }^{56}$ - Fig. 3 shows the study design for CASTA-DIVA.

\section{COSIMO: Cancer-Associated Thrombosis- Patient-Reported Outcomes with Rivaroxaban (a Noninterventional Study on Patients Changing to Rivaroxaban for Treatment of VTE and Prevention of Recurrent VTE in Patients with Active Cancer)}

COSIMO is an international, prospective, noninterventional cohort study. ${ }^{57}$ This study uses the Anti-Clot Treatment Scale (ACTS), a 15-item patient-reported validated instrument that monitors patient satisfaction. The ACTS includes a 12-item ACTS burdens scale and a 3-item ACTS benefits scale. ${ }^{58}$

The aim of the study is to assess patient-reported treatment satisfaction according to the ACTS burden score for the use of rivaroxaban for the treatment of VTE and/or prevention of recurrent VTE in patients with active cancer switching to rivaroxaban therapy. ${ }^{57}$ The primary objective of the study is measurement of patient-reported treatment satisfaction based on the ACTS burden score. Other outcomes include treatment satisfaction over time, patient preferences and patient quality of life. ${ }^{57}$ Approximately 500 patients are anticipated for the enrolment in the COSIMO study. - Fig. 4 shows the study design for COSIMO. 


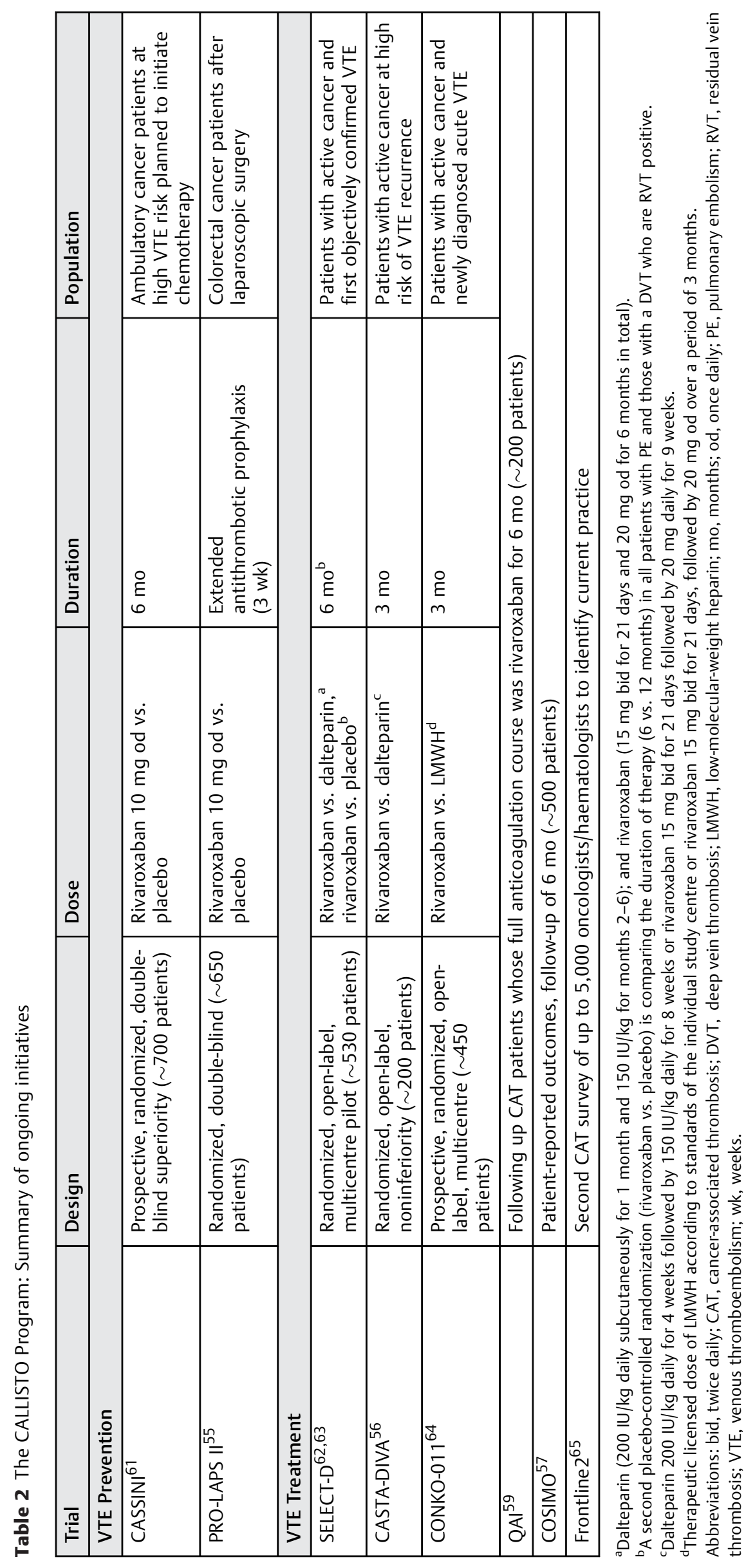




\section{PRO-LAPS II}

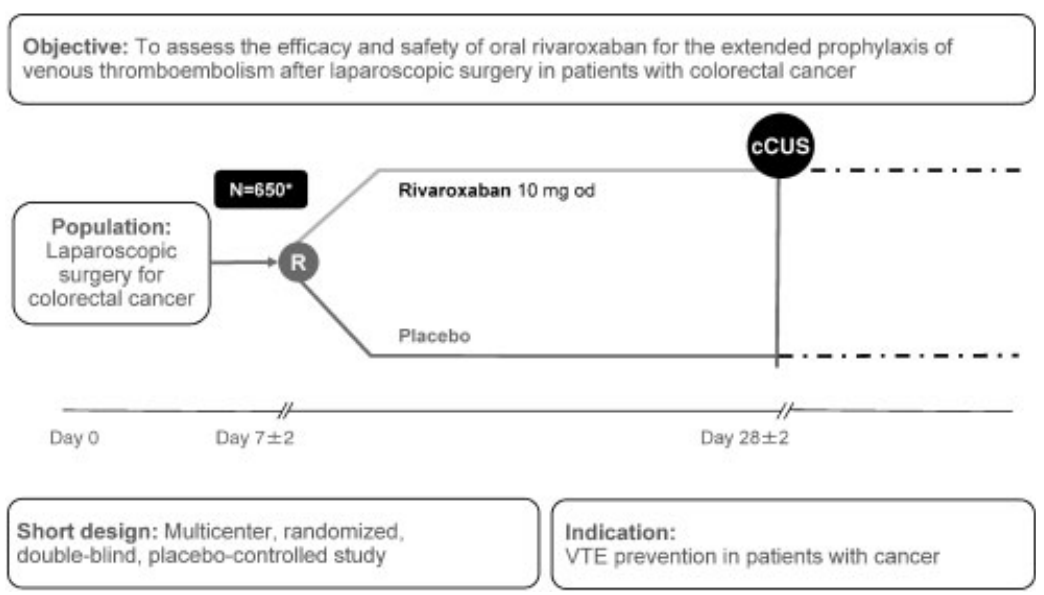

Fig. 2 PRO-LAPS II study design. ${ }^{55}$ *Estimated enrolment. Abbreviations: cCUS, complete compression ultrasound; od, once daily; $\mathrm{R}$, randomized; VTE, venous thromboembolism.

\section{CASTA-DIVA}

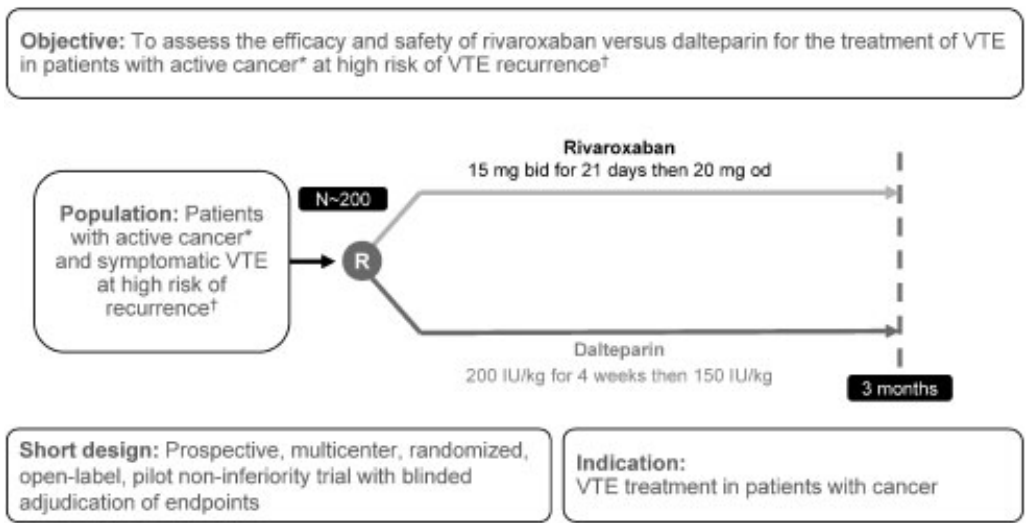

Fig. 3 CASTA-DIVA study design. ${ }^{56}$ *Presence of measurable disease or ongoing/planned chemotherapy, radiotherapy or targeted therapy. ${ }^{\dagger}$ Assessed using the modified Ottawa score. Abbreviations: Bid, twice daily; od, once daily; VTE, venous thromboembolism.

\section{COSIMO}

Objective: To assess patient-reported treatment satisfaction with regard to the ACTS burden score for
the use of rivaroxaban for treatment of VTE and/or prevention of recurrent VTE in patients with active
cancer changing to this therapy
cancer changing to this therapy

\begin{tabular}{|c|c|c|c|c|c|}
\hline \multirow{2}{*}{$\begin{array}{c}\text { Population: } \\
\text { Patients with } \\
\text { active cancer } \\
\text { and PE/DVT } \\
\text { and/or recurrent } \\
\text { PE/DVT }\end{array}$} & \multirow{3}{*}{$\begin{array}{c}\text { Treatment with } \\
\text { SOC } \\
\text { anticoagulation } \\
\text { (LMWH/VKA) } \\
\text { for } \geq 4 \text { weeks } \\
\text { prior to } \\
\text { inclusion }\end{array}$} & \multirow{2}{*}{$\begin{array}{c}\text { Decision to } \\
\text { change to } \\
\text { rivaroxaban } \\
\mathrm{N} \sim 500\end{array}$} & \multirow{2}{*}{\multicolumn{2}{|c|}{$\begin{array}{c}\text { DCE } \\
\text { 4-12 weeks after start with } \\
\text { rivaroxaban/telephone interview } \\
\text { Observation period: } 6 \text { months }\end{array}$}} & \multirow[b]{3}{*}{$\widehat{A}$} \\
\hline & & & & & \\
\hline & & ACTS & ACTS & ACTS & \\
\hline & & Baseline & $\begin{array}{l}\text { Month } 1 \\
\text { (primary endpoint) }\end{array}$ & Month 3 & Month 6 \\
\hline \multicolumn{3}{|c|}{$\begin{array}{l}\text { Short design: International, prospective, } \\
\text { non-interventional cohort study }\end{array}$} & \multicolumn{3}{|c|}{$\begin{array}{l}\text { Indication: VTE treatment and/or prevention of } \\
\text { recurrent VTE in patients with active cancer }\end{array}$} \\
\hline
\end{tabular}

Fig. 4 COSIMO study design. ${ }^{57}$ Abbreviations: ACTS, anticlot treatment scale; DCE, discrete choice experiment; DVT, deep vein thrombosis; LMWH, low-molecular-weight heparin; PE, pulmonary embolism; SOC, standard of care; VKA, vitamin K antagonist; VTE, venous thromboembolism. 


\section{Conclusion}

Several studies have emerged recently that seek to close knowledge gaps in VTE management: the novel 'umbrella' program, CALLISTO, involves multiple parallel clinical initiatives with a variety of study designs addressing hypotheses in patients with CAT, or who are at risk of VTE. Published findings to date from the Quality Assessment Initiative (QAI) conducted in 200 patients with active cancer and symptomatic proximal DVT or PE at Memorial Sloan Kettering showed that rivaroxaban had favorable safety and efficacy when it was incorporated into a clinical pathway that provided guidance for its use in the oncology setting. ${ }^{59}$ Future CALLISTO data will hopefully reduce the burden and consequences of CAT for patients with malignancy. With regards to extended VTE treatment, the EINSTEIN CHOICE data provide expanded treatment options with two rivaroxaban doses (10 $\mathrm{mg}$ or $20 \mathrm{mg}$ od), depending on the patient benefit-risk profile. Findings from such studies may ultimately lead to more comprehensive treatment strategies for optimal VTE management in the short and long term, particularly for those who have had limited options to date.

\section{What is known about this topic?}

Venous thromboembolism (VTE) presents a continuing clinical burden to healthcare systems and there are patient groups for whom VTE management is challenging. Depending on patient characteristics, the optimal duration of anticoagulation for VTE treatment can be unclear. Another group that is challenging to treat in the context of VTE is patients with cancer-associated thrombosis (CAT). In the prevention and treatment of CAT, there are limited or no data from randomized trials trials comparing nonvitamin $\mathrm{K}$ antagonist oral anticoagulants (NOACs) with vitamin $\mathrm{K}$ antagonists or low molecular weight heparin.

\section{What does this paper add?}

In the setting of extended VTE treatment, novel data from the Phase III EINSTEIN CHOICE trial are summarized, which subsequently led to label updates by both the European Medicines Agency and the Food and Drug Administration to include extended prevention of recurrent VTE with rivaroxaban $10 \mathrm{mg}$ once daily following $\geq 6$ months of standard anticoagulation therapy. The 'umbrella' program, Cancer Associated thrombosis - expLoring soLutions for patlentS through Treatment and prevention with rivarOxaban (CALLISTO), involves multiple parallel clinical initiatives with a variety of study designs addressing hypotheses in patients with CAT, or who are at risk of VTE. Several of the studies are a focus of this article. Future CALLISTO findings may help to reduce the burden and consequences of CAT for patients with malignancy.
Conflicts of Interest

A.K. is a consultant/advisory board member for Janssen, Sanofi, Leo Pharma, Bayer AG, Halozyme, Pfizer, Genentech, AngioDynamics, Boehringer Ingelheim and Daiichi Sankyo. J.W. has served as a consultant and has received honoraria from IONIS Pharmaceuticals, Janssen, Bayer AG, Boehringer Ingelheim, Bristol-Myers Squibb, Pfizer, Merck and Daiichi Sankyo.

\section{Acknowledgements}

The authors would like to acknowledge Kelly Farrell at Ketchum (Inspired Science), who provided editorial support with funding from Bayer AG.

\section{References}

1 Heit J. Poster 68. American Society of Hematology 47th Annual Meeting; Atlanta, GA; December 10-13, 2005

2 Leavitt M. The Surgeon General's Call to Action to Prevent Deep Vein Thrombosis and Pulmonary Embolism. U.S. Office of the Surgeon General; 2008

3 Geerts WH, Bergqvist D, Pineo GF, et al. Prevention of venous thromboembolism: American College of Chest Physicians Evidence-Based Clinical Practice Guidelines (8th Edition). Chest 2008;133(6, Suppl):381S-453S

4 Cohen AT, Agnelli G, Anderson FA, et al; VTE Impact Assessment Group in Europe (VITAE). Venous thromboembolism (VTE) in Europe. The number of VTE events and associated morbidity and mortality. Thromb Haemost 2007;98(04):756-764

5 Heit JA. Epidemiology of venous thromboembolism. Nat Rev Cardiol 2015;12(08):464-474

6 Kearon C, Akl EA, Ornelas J, et al. Antithrombotic therapy for VTE disease: CHEST guideline and expert panel report. Chest 2016; 149(02):315-352

7 Khorana AA, Francis CW, Culakova E, Kuderer NM, Lyman GH. Frequency, risk factors, and trends for venous thromboembolism among hospitalized cancer patients. Cancer 2007;110 (10):2339-2346

8 Lyman GH, Khorana AA, Falanga A, et al; American Society of Clinical Oncology. American Society of Clinical Oncology guideline: recommendations for venous thromboembolism prophylaxis and treatment in patients with cancer. J Clin Oncol 2007;25 (34):5490-5505

9 Prandoni P, Lensing AWA, Büller HR, et al. Deep-vein thrombosis and the incidence of subsequent symptomatic cancer. $\mathrm{N}$ Engl J Med 1992;327(16):1128-1133

10 Heit JA, Silverstein MD, Mohr DN, Petterson TM, O'Fallon WM, Melton LJ III. Risk factors for deep vein thrombosis and pulmonary embolism: a population-based case-control study. Arch Intern Med 2000;160(06):809-815

11 Khorana AA, Francis CW, Culakova E, Kuderer NM, Lyman GH. Thromboembolism is a leading cause of death in cancer patients receiving outpatient chemotherapy. J Thromb Haemost 2007;5 (03):632-634

12 Prandoni P, Noventa F, Ghirarduzzi A, et al. The risk of recurrent venous thromboembolism after discontinuing anticoagulation in patients with acute proximal deep vein thrombosis or pulmonary embolism. A prospective cohort study in 1,626 patients. Haematologica 2007;92(02):199-205

13 van der Hulle T, Tan M, den Exter PL, et al. Recurrence risk after anticoagulant treatment of limited duration for late, second venous thromboembolism. Haematologica 2015;100(02): 188-193

14 Bauersachs R, Berkowitz SD, Brenner B, et al; EINSTEIN Investigators. Oral rivaroxaban for symptomatic venous thromboembolism. N Engl J Med 2010;363(26):2499-2510 
15 Büller HR, Prins MH, Lensin AW, et al; EINSTEIN-PE Investigators. Oral rivaroxaban for the treatment of symptomatic pulmonary embolism. N Engl J Med 2012;366(14):1287-1297

16 Bayer AG. Xarelto Summary of Product Characteristics. Available at: http://www.ema.europa.eu/ema/index.jsp?curl=pages/ medicines/human/medicines/000944/human_med_001155. jsp\&mid=WC0b01ac058001d124; Accessed January 31, 2018

17 Birocchi S, Scannella E, Ferrari L, Podda GM; Gruppo di Autoformazione Metodologica (GrAM). Aspirin in the secondary prevention of unprovoked thromboembolism: the WARFASA and ASPIRE studies. Intern Emerg Med 2013;8(08):757-760

18 Weitz JI, Bauersachs R, Beyer-Westendorf J, et al; EINSTEIN CHOICE Investigators. Two doses of rivaroxaban versus aspirin for prevention of recurrent venous thromboembolism. Rationale for and design of the EINSTEIN CHOICE study. Thromb Haemost 2015;114(03):645-650

19 Weitz JI, Lensing AWA, Prins MH, et al; EINSTEIN CHOICE Investigators. Rivaroxaban or aspirin for extended treatment of venous thromboembolism. N Engl J Med 2017;376(13): 1211-1222

20 Boonyawat K, Lensing A, Prins $\mathrm{M}$, et al. Menstrual Bleeding Patterns in Women Treated with Rivaroxaban: Data from the EINSTEIN CHOICE Trial. ISTH Academy; 2017

21 Janssen Pharmaceuticals, Inc. FDA Approves New 10 mg Dosing for XARELTO ${ }^{\circledR}$ (rivaroxaban) to Reduce the Continued Risk of Venous Thromboembolism (VTE). Available at: https://www.jnj. $\mathrm{com} /$ media-center/press-releases/fda-approves-new-10-mgdosing-for-xarelto-rivaroxaban-to-reduce-the-continued-risk-ofvenous-thromboembolism-vte; Accessed January 31, 2018

22 PharmaTimes online. EU OKs low-dose Xarelto to prevent recurrent VTE. Available at: http://www.pharmatimes.com/news/eu_oks_lowdose_xarelto_to_prevent_recurrent_vte_1210333; Accessed January 31, 2018

23 Agnelli G, Buller HR, Cohen A, et al; AMPLIFY-EXT Investigators. Apixaban for extended treatment of venous thromboembolism. N Engl J Med 2013;368(08):699-708

24 Donnellan E, Kevane B, Bird BR, Ainle FN. Cancer and venous thromboembolic disease: from molecular mechanisms to clinical management. Curr Oncol 2014;21(03):134-143

25 Stein PD, Beemath A, Meyers FA, Skaf E, Sanchez J, Olson RE. Incidence of venous thromboembolism in patients hospitalized with cancer. Am J Med 2006;119(01):60-68

26 Prandoni P, Lensing AW, Piccioli A, et al. Recurrent venous thromboembolism and bleeding complications during anticoagulant treatment in patients with cancer and venous thrombosis. Blood 2002;100(10):3484-3488

27 Khorana AA, Carrier M, Garcia DA, Lee AY. Guidance for the prevention and treatment of cancer-associated venous thromboembolism. J Thromb Thrombolysis 2016;41(01):81-91

28 Noble S, Matzdorff A, Maraveyas A, Holm MV, Pisa G. Assessing patients' anticoagulation preferences for the treatment of cancerassociated thrombosis using conjoint methodology. Haematologica 2015;100(11):1486-1492

29 Blom JW, Vanderschoot JP, Oostindiër MJ, Osanto S, van der Meer FJ, Rosendaal FR. Incidence of venous thrombosis in a large cohort of 66,329 cancer patients: results of a record linkage study. J Thromb Haemost 2006;4(03):529-535

30 Thrombosis Adviser. VTE in patients with cancer. Available at: https://www.thrombosisadviser.com/VTE-in-Patients-with-Cancer/; Accessed January 31, 2018

31 Gould MK, Garcia DA, Wren SM, et al. Prevention of VTE in nonorthopedic surgical patients: Antithrombotic Therapy and Prevention of Thrombosis, 9th ed: American College of Chest Physicians Evidence-Based Clinical Practice Guidelines. Chest 2012;141(2, Suppl):e227S-e77S

32 Lyman GH, Khorana AA, Kuderer NM, et al; American Society of Clinical Oncology Clinical Practice. Venous thromboembolism prophylaxis and treatment in patients with cancer: American
Society of Clinical Oncology clinical practice guideline update. J Clin Oncol 2013;31(17):2189-2204

33 Watson HG, Keeling DM, Laffan M, Tait RC, Makris M; British Committee for Standards in Haematology. Guideline on aspects of cancer-related venous thrombosis. Br J Haematol 2015;170(05): 640-648

34 Mandalà M, Falanga A, Roila F; ESMO Guidelines Working Group. Management of venous thromboembolism (VTE) in cancer patients: ESMO Clinical Practice Guidelines. Ann Oncol 2011;22 (Suppl 6):vi85-vi92

35 Mandalà M, Falanga A, Roila F; ESMO Guidelines Working Group. Venous thromboembolism in cancer patients: ESMO Clinical Practice Guidelines for the management. Ann Oncol 2010;21 (Suppl 5):v274-v276

36 Khorana AA, Kuderer NM, Culakova E, Lyman GH, Francis CW. Development and validation of a predictive model for chemotherapy-associated thrombosis. Blood 2008;111(10):4902-4907

37 Angelini D, Khorana AA. Risk assessment scores for cancerassociated venous thromboembolic disease. Semin Thromb Hemost 2017;43(05):469-478

38 Akl EA, Kahale L, Barba M, et al. Anticoagulation for the long-term treatment of venous thromboembolism in patients with cancer. Cochrane Database Syst Rev 2014;(07):CD006650

39 Lee AY, Kamphuisen PW, Meyer G, et al; CATCH Investigators. Tinzaparin vs warfarin for treatment of acute venous thromboembolism in patients with active cancer: a randomized clinical trial. JAMA 2015;314(07):677-686

40 Lee AY, Levine MN, Baker RI, et al; Randomized Comparison of Low-Molecular-Weight Heparin versus Oral Anticoagulant Therapy for the Prevention of Recurrent Venous Thromboembolism in Patients with Cancer (CLOT) Investigators. Low-molecular-weight heparin versus a coumarin for the prevention of recurrent venous thromboembolism in patients with cancer. N Engl J Med 2003;349 (02):146-153

41 Ho PM, Bryson CL, Rumsfeld JS. Medication adherence: its importance in cardiovascular outcomes. Circulation 2009;119(23): 3028-3035

42 Khorana AA, Yannicelli D, McCrae KR, et al. Evaluation of US prescription patterns: Are treatment guidelines for cancer-associated venous thromboembolism being followed? Thromb Res 2016;145:51-53

43 Khorana AA, McCrae KR, Milentijevic D, et al. Current practice patterns and patient persistence with anticoagulant treatments for cancer-associated thrombosis. Res Pract Thromb Haemost 2017;1(01):14-22

44 Prins MH, Lensing AW, Bauersachs R, et al; EINSTEIN Investigators. Oral rivaroxaban versus standard therapy for the treatment of symptomatic venous thromboembolism: a pooled analysis of the EINSTEIN-DVT and PE randomized studies. Thromb J 2013;11(01):21

45 Prins MH, Lensing AW, Brighton TA, et al. Oral rivaroxaban versus enoxaparin with vitamin $\mathrm{K}$ antagonist for the treatment of symptomatic venous thromboembolism in patients with cancer (EINSTEINDVT and EINSTEIN-PE): a pooled subgroup analysis of two randomised controlled trials. Lancet Haematol 2014;1(01):e37-e46

46 Agnelli G, Buller HR, Cohen A, et al. Oral apixaban for the treatment of venous thromboembolism in cancer patients: results from the AMPLIFY trial. J Thromb Haemost 2015;13(12): 2187-2191

47 Raskob GE, van Es N, Segers A, et al; Hokusai-VTE Investigators. Edoxaban for venous thromboembolism in patients with cancer: results from a non-inferiority subgroup analysis of the HokusaiVTE randomised, double-blind, double-dummy trial. Lancet Haematol 2016;3(08):e379-e387

48 Schulman S, Goldhaber SZ, Kearon C, et al. Treatment with dabigatran or warfarin in patients with venous thromboembolism and cancer. Thromb Haemost 2015;114(01):150-157

49 van Es N, Coppens M, Schulman S, Middeldorp S, Büller HR. Direct oral anticoagulants compared with vitamin $\mathrm{K}$ antagonists for 
acute venous thromboembolism: evidence from phase 3 trials. Blood 2014;124(12):1968-1975

50 ADAM-VTE. ClinicalTrials.gov Identifier: NCT02585713. Available at: https://clinicaltrials.gov/ct2/show/NCT02585713; Accessed January 31, 2018

51 Cancer HOKUSAI-VTE. ClinicalTrials.gov Identifier: NCT02073682. Available at: https://clinicaltrials.gov/ct2/show/NCT02073682; Accessed January 31, 2018

52 CARAVAGGIO. ClinicalTrials.gov Identifier: NCT03045406. Available at: https://clinicaltrials.gov/ct2/show/NCT03045406; Accessed January 31, 2018

53 CANVAS. ClinicalTrials.gov Identifier: NCT02744092. Available at: https://clinicaltrials.gov/ct2/show/NCT02744092; Accessed January 31, 2018

54 Bach M, Bauersachs R. Spotlight on advances in VTE management: CALLISTO and EINSTEIN CHOICE. Thromb Haemost 2016;116 (Suppl 2):S24-S32

55 PRO-LAPSII. ClinicalTrials.gov Identifier: NCT03055026. Available at: https://clinicaltrials.gov/ct2/show/NCT03055026; Accessed January 31, 2018

56 CASTA-DIVA. ClinicalTrials.gov Identifier: NCT02746185. Available at: https://clinicaltrials.gov/ct2/show/NCT02746185; Accessed January 31, 2018

57 COSIMO. ClinicalTrials.gov Identifier: NCT02742623. Available at: https://clinicaltrials.gov/ct2/show/NCT02742623; Accessed January 31,2018

58 Cano SJ, Lamping DL, Bamber L, Smith S. The anti-clot treatment scale (ACTS) in clinical trials: cross-cultural validation in venous thromboembolism patients. Health Qual Life Outcomes 2012; $10: 120$

59 Mantha S, Laube E, Miao Y, et al. Safe and effective use of rivaroxaban for treatment of cancer-associated venous thromboembolic disease: a prospective cohort study. J Thromb Thrombolysis 2017;43(02):166-171

60 Konstantinides SV, Torbicki A, Agnelli G, et al; Task Force for the Diagnosis and Management of Acute Pulmonary Embolism of the European Society of Cardiology (ESC). 2014 ESC guidelines on the diagnosis and management of acute pulmonary embolism. Eur Heart J 2014;35(43):3033-3069, 3069a-3069k

61 CASSINI. ClinicalTrials.gov Identifier: NCT02555878. Available at: https://ClinicalTrials.gov/show/NCT02555878; Accessed January 31,2018

62 Warwick Clinical Trials Unit. SELECT-D. Anticoagulation Therapy in SELECTeD Cancer Patients at risk of recurrence of venous thromboembolism. Available at: http://www2.warwick.ac.uk/ fac/med/research/hscience/ctu/trials/cancer/select-d/; Accessed January 31, 2018

63 Young A, Phillips J, Hancocks H, et al. OC-11 - Anticoagulation therapy in selected cancer patients at risk of recurrence of venous thromboembolism. Thromb Res 2016;140(Suppl 1):S172-S173

64 CONKO-011. ClinicalTrials.gov Identifier: NCT02583191. Available at: https://ClinicalTrials.gov/show/NCT02583191; Accessed January 31, 2018

65 Thrombosis Research Institute. Frontline2. Fundamental Research in Oncology and Thrombosis (FRONTLINE 2) Survey. Available at: http://frontline2.tri-london.ac.uk/; Accessed January 31, 2018 